\title{
Accuracy of clinical diagnosis for the identification of potentially malignant disorders and malignant lip lesions
}

\section{Marina CURRA(a) \\ Gabriela SALVADORI(b) \\ Roger JUNGES(b) \\ Manoel SANT'ANA FILHO(a) \\ Fernando Neves HUGO(c) \\ Manoela Domingues MARTINS(a)}

(a) Universidade Federal do Rio Grande do Sul - UFRGS, School of Dentistry, Department of Oral Pathology, Porto Alegre, RS, Brazil.

(b) University of Oslo, Faculty of Dentistry, Department of Oral Biology, Oslo, Norway.

(c) Universidade Federal do Rio Grande do Sul - UFRGS, School of Dentistry, Center of Community Dental Health Research, Porto Alegre, RS, Brazil.

Declaration of Interests: The authors certify that they have no commercial or associative interest that represents a conflict of interest in connection with the manuscript.

\section{Corresponding Author:}

Manoela Domingues Martins

Email:manomartins@gmail.com

DOI: 10.1590/1807-3107BOR-2016.vol30.0135

Submitted: May 12, 2016

Accepted for publication: Sep 23, 2016

Last revision: Oct 26, 2016

\begin{abstract}
The aim of this study was to assess the accuracy of clinical diagnosis for lip lesions based on sensitivity and specificity. The retrospective analysis focused on the detection of lesions caused by potentially malignant disorders (PMDs) and malignant lesions ( $\mathrm{n}=1195)$. All cases were classified as benign, PMD, and malignant lesions. Concordance between diagnoses based on clinical examination and those based on histopathological analysis was assessed, and accuracy for the identification of PMD and malignant lesions was calculated. Histopathological analysis revealed 44 lesion types; PMD and malignant lesions comprised $8.3 \%$ of all cases. Compared with histopathological analysis, clinical examination showed 97.4\% accuracy for the identification of non-malignant and potentially malignant/malignant cases. Degrees of specific sensitivity ranged from $34 \%$ to $77 \%$ for different lesions, and were highest for autoimmune (77\%) and reactive (72\%) lesions. Positive and negative predictive values for the identification of PMD and malignant lesions were 81.9\% and $98.9 \%$, respectively. Clinical examination showed a high degree of accuracy for the detection of PMD and malignant lip lesions, indicating good reliability.
\end{abstract}

Keywords: lip disease; clinical diagnosis; neoplasm.

\section{Introduction}

The burden of oral and nasopharyngeal cancer is importunate, as more than 48,000 new cases and 9,500 deaths are estimated to occur in the US alone in 2016. In 2012, an estimated 387,000 new cases and more than 196,000 deaths due to this cancer occurred worldwide. ${ }^{2}$ Between 1979 and 2002 , more than 78,000 deaths due to oral and nasopharyngeal cancer were recorded in Brazil. ${ }^{3}$ The average 5 -year survival rate for cancer at these sites is $63.2 \% .4,5,6$ This estimate has increased over the past few decades, and ranges from $37 \%$ and $83 \%$, depending on location and stage at the time of diagnosis. ${ }^{6}$

Due to their anatomic location, the lips are exposed to a variety of irritants and carcinogenic agents; factors such as ultraviolet (UV) radiation, tobacco, food, and trauma can alter the normal tissue integrity. ${ }^{7,9}$ In addition, the lips form a transitional zone between the mucosal tissues and the skin; thus, the characteristics of lip cancer differ from those of other oral cavity and nasopharyngeal malignancies. In 2010, 6\% of all new cases 
of cancer in the oral cavity and pharynx in the UK were located in the lips. ${ }^{10}$ Although this form of the disease is associated with favorable 5-year survival rates, ranging from $52 \%$ to $93 \%$, 10,11 the early diagnosis of such cases is of concern. ${ }^{12,13}$ The reported prevalence of malignancy among lip lesions ranges from $12 \%$ to $21 \%{ }^{14,15}$ In addition, despite the favorable survival rates for lip cancer, the consequences of surgical resection are important factors that can impair quality of life. ${ }^{16}$

Conventional clinical oral examination has long been the standard method for the assessment of oral lesions, including those caused by potentially malignant disorders (PMDs), and for oral cancer screening. ${ }^{17,18}$ Clinical evaluation of the lip region is facilitated by the anatomic location. However, oral examination alone is not sufficient for the detection and accurate distinction of benign, PMD, and malignant lesions. ${ }^{19,20}$ Clinical screening followed by histopathological analysis is crucial, given the estimated annual number of new lip cancer cases worldwide and the wide range of lesions that occur in this location. ${ }^{21,22}$ Biopsy, paired with clinical examination, is recommended for final diagnosis; in addition, this approach is recommended when lesions persist despite treatment or the removal of local irritants (of traumatic or inflammatory origin), when lesions do not recede in 2 weeks, when malignancy is suspected, and when lesions interfere with function or impair aesthetics. ${ }^{23}$

The rate of concordance between clinical and histopathological diagnoses of oral lesions ranges from $36 \%$ to $50 \%{ }^{24,25,26,27}$ In contrast, a few studies have reported high degrees of sensitivity and specificity, and high positive predictive value, of clinical oral examination for the detection of malignancies, $28,29,30$ indicating that the initial clinical evaluation is reliable for the early detection of malignant and PMD lesions. More importantly, clinicians' decision making following such examination can be supported by knowledge of diagnostic accuracy. To our knowledge, no study has assessed the diagnostic accuracy and predictive value of PMDs and malignant lesions with a focus on the lip region.

The aim of this study was to determine the diagnostic accuracy of lip lesions in a retrospective analysis of clinical and histopathological aspects and distribution of lip lesions in a large sample of patients.

\section{Methodology}

\section{Study design and sample}

This retrospective study was conducted using data from the Department of Oral Pathology of the School of Dentistry, Federal University of Rio Grande do Sul (UFRGS), Porto Alegre, Brazil. Private and public dentists, and predominantly undergraduate and graduate students of the institution, submit specimens to the laboratory for histopathological examination. In addition, the laboratory receives samples obtained for research purposes via experimental studies conducted at the school. Data on lip biopsy specimens recorded between 1946 and 2011 were retrieved from the laboratory. Data on patients' demographic characteristics (sex, age, and ethnicity), clinical data (location and diagnostic hypothesis), and histopathological (final) diagnoses were collected.

\section{Outcome classification}

Self-reported ethnicity was classified using the terms "white," "brown," and "black." The location of lip lesions was classified as lower lip, upper lip, commissure, and not specified. Lesions located on the internal parts of the lips were also included. For clinical and histopathological diagnoses, lesions were divided into seven groups: disorders of epithelial maturation (G1), autoimmune lesions (G2), reactive lesions (G3), infectious lesions (G4), benign neoplasms (G5), malignant neoplasms (G6), and other (G7). For further analyses, all lesions were divided into three groups: benign (G1-G5, G7), PMD (part of G1), and malignant (G6). More specifically, lesions with histopathological diagnoses of actinic cheilitis and cases of epithelial dysplasia (initially assigned to G1) were placed in the PMD group. ${ }^{31}$ The final outcome classification was based on histopathological diagnoses.

\section{Statistical analysis}

Data were analyzed using the Statistical Package for the Social Sciences (SPSS; version 20 for Macintosh; 
SPSS Inc., Chicago, USA). The individual was used as the unit of analysis, and the significance level was set at 5\%. Demographic, clinical, and histopathological data were evaluated by the sensitivity test and Fisher's exact test. Diagnostic accuracy was calculated based on the sensitivity, specificity, likelihood ratio, and predictive value; the final classification of diagnoses (benign, potentially malignant, and malignant) was used for this assessment. The cutoff values used to interpret sensitivity were $>80 \%$ (excellent), $70-80 \%$ (good), 60-69\% (fair), and $<60 \%$ (poor); those used for specificity were $>90 \%$ (excellent), $80-90 \%$ (good), $70-79 \%$ (fair), and $<70 \%$ (poor). ${ }^{32}$

\section{Ethical approval}

The use of human subject data followed the ethical requirements of, and was approved by, the Institutional Review Board of UFRGS.

\section{Results}

\section{Sample}

UFRGS's Laboratory of Oral Pathology received a total of 1195 lip biopsy specimens from 1946 through 2011; all were included in this study. Overall analysis showed that 44 histopathological lesion types were recorded. Table 1 shows the distribution of lesions within groups according to anatomic location, and patients' sex and age.

\section{Frequency and demographic distribution}

A slight majority (53\%) of lesion samples were from women. The average patient age was 36.2 years (standard deviation, 20.6 years; range, 3 months-96 years). In the first two decades of life, lesions were more prevalent in women; thereafter, the distribution of lesions did not differ according to sex. The majority of lesions ( $\mathrm{n}=840,70.4 \%$ ) were from white individuals. The majority $(\mathrm{n}=699$, $58.6 \%$ ) of lesions were reactive, followed by benign neoplasms ( $n=238,19.9 \%)$, disorders of epithelial maturation ( $\mathrm{n}=138,11.5 \%)$, malignant neoplasms ( $\mathrm{n}=56,4.7 \%)$, others $(\mathrm{n}=35,2.9 \%)$, infectious lesions ( $\mathrm{n}=20,1.7 \%)$, and autoimmune diseases ( $\mathrm{n}=9,0.7 \%$; Table 1$)$. The most prevalent reactive lesions were oral mucoceles $(n=453,37.9 \%)$ and those characterized by inflammatory hyperplasia ( $n=167,14 \%$ ). The most common benign neoplasms were fibromas $(n=108,9 \%)$, papillomas $(n=51$, $4.3 \%)$, and hemangiomas $(n=36,3 \%)$. Forty-seven (3.9\%) malignant neoplasms were diagnosed as oral squamous cell carcinoma (Table 1). Figure 1 shows the distribution of lesions according to histopathological type and age group.

The most common lesion location was the lower lip ( $\mathrm{n}=915,76.6 \%)$, followed by the upper lip $(\mathrm{n}=134$, $11.2 \%)$ and the commissure ( $\mathrm{n}=70,5.8 \%)$. On the lower lip, $49.1 \%(n=587)$ of lesions were reactive, followed by benign neoplasms ( $n=151,12.6 \%)$. The same pattern was observed for the upper lip (reactive lesions: $n=62,5.2 \%$; benign neoplasms: $n=39,3.3 \%$ ). Fibromas were the most prevalent lesions on the commissure $(n=19,1.6 \%$; Table 1$)$.

Seventy-seven $(8.3 \%)$ cases were diagnosed as malignant or PMD lesions, based on histopathological analysis. The majority of patients diagnosed with malignant lesions were in their fourth (20.4\%) and fifth (32\%) decades of life (Figure 2). The lower lip was the predominant site of PMD $(n=36,76.6 \%)$ and malignant $(n=43,76.8 \%)$ lesions.

\section{Sensitivity of clinical diagnosis for all lesions}

Sensitivity values for all lesion groups are presented in Table 2. For this analysis, we treated all cases of missed clinical diagnosis under the assumption that the clinicians who performed the biopsies had no diagnostic hypothesis. Sensitivity values were greatest for autoimmune and reactive lesions ( $77 \%$ and $72 \%$, respectively). Table 3 shows the distribution of clinical diagnostic hypotheses and final histopathological diagnoses stratified by malignant, PMD, and non-malignant lesions. No clinical diagnosis was recorded for 185 (15.5\%) cases, and two diagnostic hypotheses (differential diagnosis) were recorded for 18 (1.5\%) cases. After the exclusion of cases with descriptive histopathological diagnoses and those with no clinical diagnostic hypothesis, the concordance between the provisional and final diagnoses was calculated: these values were $88.3 \%$ for PMD and malignant lesions and 98.2\% for non-malignant lesions ( $p<0.001$; Table 4 ). 
Table 1. Histopathological distribution of lip lesions according to gender, age and affected site $(n=1195)$.

\begin{tabular}{|c|c|c|c|c|c|c|c|}
\hline \multirow{2}{*}{ Groups } & \multirow{2}{*}{ n (\%) } & \multicolumn{2}{|c|}{ Gender n (\%) } & \multicolumn{3}{|c|}{ Site $\mathrm{n}(\%)$} & \multirow{2}{*}{$\mathrm{NI},(\mathrm{n} \%)$} \\
\hline & & Male & Female & Lower Lip & Upper Lip & Comissure & \\
\hline \multicolumn{8}{|l|}{ G1 } \\
\hline Epithelial hyperplasia & $40(3.3)$ & $12(1)$ & $28(2.3)$ & $28(2.3)$ & $3(0.2)$ & $5(0.4)$ & $4(0.3)$ \\
\hline Actinic Cheilitis & $38(3.2)$ & $28(2.3)$ & $10(0.8)$ & $31(2.6)$ & $2(0.2)$ & $1(0.1)$ & $4(0.3)$ \\
\hline Hyperkeratosis & $26(2.2)$ & $22(1.8)$ & $4(0.3)$ & $9(0.7)$ & $13(1.1)$ & $2(0.2)$ & $2(0.2)$ \\
\hline Acantosis + Hyperkeratosis & $22(1.8)$ & $17(1.4)$ & $5(0.4)$ & $13(1.1)$ & $3(0.2)$ & $5(0.4)$ & $1(0.1)$ \\
\hline Epithelial dysplasia & $9(0.7)$ & $8(0.7)$ & $1(0.1)$ & $5(0.4)$ & $2(0.2)$ & $1(0.1)$ & $1(0.1)$ \\
\hline Hyperkeratosis + Melanosis & $2(0.2)$ & $1(0.1)$ & $1(0.1)$ & $2(0.2)$ & - & - & - \\
\hline Cutaneous Horn & $1(0.1)$ & $1(0.1)$ & - & - & - & $1(0.1)$ & - \\
\hline Total & $138(11.5)$ & $89(7.4)$ & $49(4.1)$ & $88(7.4)$ & $23(1.9)$ & $15(1.2)$ & $12(1)$ \\
\hline \multicolumn{8}{|l|}{ G2 } \\
\hline Lichen planus & $6(0.5)$ & - & $6(0.5)$ & - & $2(0.2)$ & $1(0.1)$ & $3(0.2)$ \\
\hline Penfigus vulgaris & $2(0.2)$ & $1(0.1)$ & $1(0.1)$ & $2(0.2)$ & - & - & - \\
\hline Sjögren Syndrome & $1(0.1)$ & $1(0.1)$ & - & $1(0.1)$ & - & - & - \\
\hline Total & $9(0.7)$ & $2(0.2)$ & $7(0.6)$ & $3(0.2)$ & $2(0.2)$ & $1(0.1)$ & $3(0.2)$ \\
\hline \multicolumn{8}{|l|}{ G3 } \\
\hline Mucocele & $453(37.9)$ & $221(18.5)$ & $232(19.4)$ & $433(36.2)$ & $14(1.2)$ & $3(0.2)$ & $3(0.2)$ \\
\hline Inflamatory hyperplasia & $167(14)$ & $54(4.5)$ & $113(9.4)$ & $120(10)$ & $37(3.1)$ & $7(0.6)$ & $3(0.2)$ \\
\hline Pyogenic granuloma & $33(2.8)$ & $14(1.2)$ & $19(1.6)$ & $23(1.9)$ & $8(0.7)$ & $1(0.1)$ & $1(0.1)$ \\
\hline Cronic inflamation & $24(2)$ & $8(0.7)$ & $16(1.3)$ & $3(0.2)$ & - & $10(0.8)$ & $11(0.9)$ \\
\hline Fibrosis & $7(0.6)$ & $3(0.2)$ & $4(0.3)$ & - & - & - & $7(0.6)$ \\
\hline Foreign body reaction & $4(0.3)$ & $1(0.1)$ & $3(0.2)$ & $1(0.1)$ & $1(0.1)$ & $1(0.1)$ & $1(0.1)$ \\
\hline Melanosis & $3(0.2)$ & $2(0.2)$ & $1(0.1)$ & $2(0.2)$ & - & - & $1(0.1)$ \\
\hline Traumatic Ulcer & $3(0.2)$ & $2(0.2)$ & $1(0.1)$ & $2(0.2)$ & $1(0.1)$ & - & - \\
\hline Giant cell lesion & $2(0.2)$ & - & $2(0.2)$ & $1(0.1)$ & - & - & $1(0.1)$ \\
\hline Papilomatosis & $1(0.1)$ & - & $1(0.1)$ & $1(0.1)$ & - & - & - \\
\hline Keloid & $1(0.1)$ & $1(0.1)$ & - & $1(0.1)$ & - & - & - \\
\hline Necrosis & $1(0.1)$ & - & $1(0.1)$ & - & $1(0.1)$ & - & - \\
\hline Total & $699(58.6)$ & $306(25.7)$ & $393(32.9)$ & $587(49.1)$ & $62(5.2)$ & $22(1.8)$ & $28(2.2)$ \\
\hline \multicolumn{8}{|l|}{ G4 } \\
\hline Paracoccidioidomicosis & $14(1.2)$ & $13(1.1)$ & $1(0.1)$ & $14(1.2)$ & - & - & - \\
\hline Molluscum Contagiosum & $2(0.2)$ & - & $2(0.2)$ & $2(0.2)$ & - & - & - \\
\hline Verruga vulgaris & $2(0.2)$ & $1(0.1)$ & $1(0.1)$ & $2(0.2)$ & - & - & - \\
\hline Actynomicosis & $1(0.1)$ & $1(0.1)$ & - & $1(0.1)$ & - & - & - \\
\hline Leucoplastic Candida & $1(0.1)$ & - & $1(0.1)$ & - & $1(0.1)$ & - & - \\
\hline Total & $20(1.7)$ & $15(1.2)$ & $5(0.4)$ & $19(1.6)$ & $1(0.1)$ & - & - \\
\hline \multicolumn{8}{|l|}{ G5 } \\
\hline Fibroma & $108(9)$ & $34(2.8)$ & $74(6.2)$ & $75(6.3)$ & $9(0.7)$ & $19(1.6)$ & $5(0.4)$ \\
\hline Papilloma & $51(4.3)$ & $25(2.1)$ & $26(2.2)$ & $33(2.8)$ & $6(0.5)$ & - & $12(1)$ \\
\hline Hemangioma & $36(3)$ & $11(0.9)$ & $25(2.1)$ & $21(1.7)$ & $10(0.8)$ & $5(0.4)$ & - \\
\hline Lipoma & $12(1)$ & $5(0.4)$ & $7(0.6)$ & $7(0.6)$ & $5(0.4)$ & - & - \\
\hline Pleomorphic adenoma & $9(0.7)$ & $3(0.2)$ & $6(0.5)$ & $7(0.6)$ & $1(0.1)$ & $1(0.1)$ & - \\
\hline Traumatic Neuroma & $8(0.7)$ & $2(0.2)$ & $6(0.5)$ & - & $6(0.5)$ & $2(0.2)$ & - \\
\hline Keratoacanthoma & $6(0.5)$ & $3(0.2)$ & $3(0.2)$ & $6(0.5)$ & - & - & - \\
\hline Schwannoma & $4(0.3)$ & $1(0.1)$ & $3(0.2)$ & - & - & - & $4(0.3)$ \\
\hline Lymphangioma & $3(0.2)$ & $3(0.2)$ & - & $2(0.2)$ & $1(0.1)$ & - & - \\
\hline Angiomioma & $1(0.1)$ & $1(0.1)$ & - & - & $1(0.1)$ & - & - \\
\hline Total & 238 (19.9) & $88(7.4)$ & $150(12.5)$ & $151(12.6)$ & 39 (3.3) & $27(2.2)$ & $21(1.7)$ \\
\hline
\end{tabular}

Continue 


\begin{tabular}{|c|c|c|c|c|c|c|c|}
\hline \multicolumn{8}{|l|}{ Continuation } \\
\hline \multicolumn{8}{|l|}{ G6 } \\
\hline Squamous cell carcinoma & $47(3.9)$ & $41(3.4)$ & $6(0.5)$ & $40(3.3)$ & $2(0.1)$ & $3(0.2)$ & $2(0.1)$ \\
\hline Verrucous carcinoma & $6(0.5)$ & $6(0.5)$ & - & $3(0.2)$ & - & - & $3(0.2)$ \\
\hline Basocellular carcinoma & $2(0.2)$ & $1(0.1)$ & $1(0.1)$ & - & $2(0.1)$ & - & - \\
\hline Multiple endocrin neoplasia & $1(0.1)$ & - & $1(0.1)$ & - & $1(0.1)$ & - & - \\
\hline Total & $56(4.7)$ & $48(4)$ & $8(0.7)$ & $43(3.6)$ & $5(0.4)$ & $3(0.2)$ & $5(0.4)$ \\
\hline \multicolumn{8}{|l|}{ G7 } \\
\hline Benign Melanocitic Lesion & $12(1)$ & $4(0.3)$ & $8(0.6)$ & $4(0.3)$ & - & $1(0.1)$ & $7(0.6)$ \\
\hline Chronic Sialoadenitis & $12(1)$ & $5(0.4)$ & $7(0.6)$ & $12(1)$ & - & - & - \\
\hline Cystic Lesion & $11(0.9)$ & $6(0.5)$ & $5(0.4)$ & $8(0.7)$ & $2(0.2)$ & $1(0.1)$ & - \\
\hline Total & $35(2.9)$ & $15(1.2)$ & $20(1.7)$ & $24(2)$ & $2(0.2)$ & $2(0.2)$ & $7(0.6)$ \\
\hline TOTAL & 1195 (100) & $563(47.1)$ & $632(52.9)$ & 915 (76.6) & $134(11.2)$ & $70(5.8)$ & $76(6.3)$ \\
\hline
\end{tabular}

$\mathrm{Nl}$ indicates not informed.

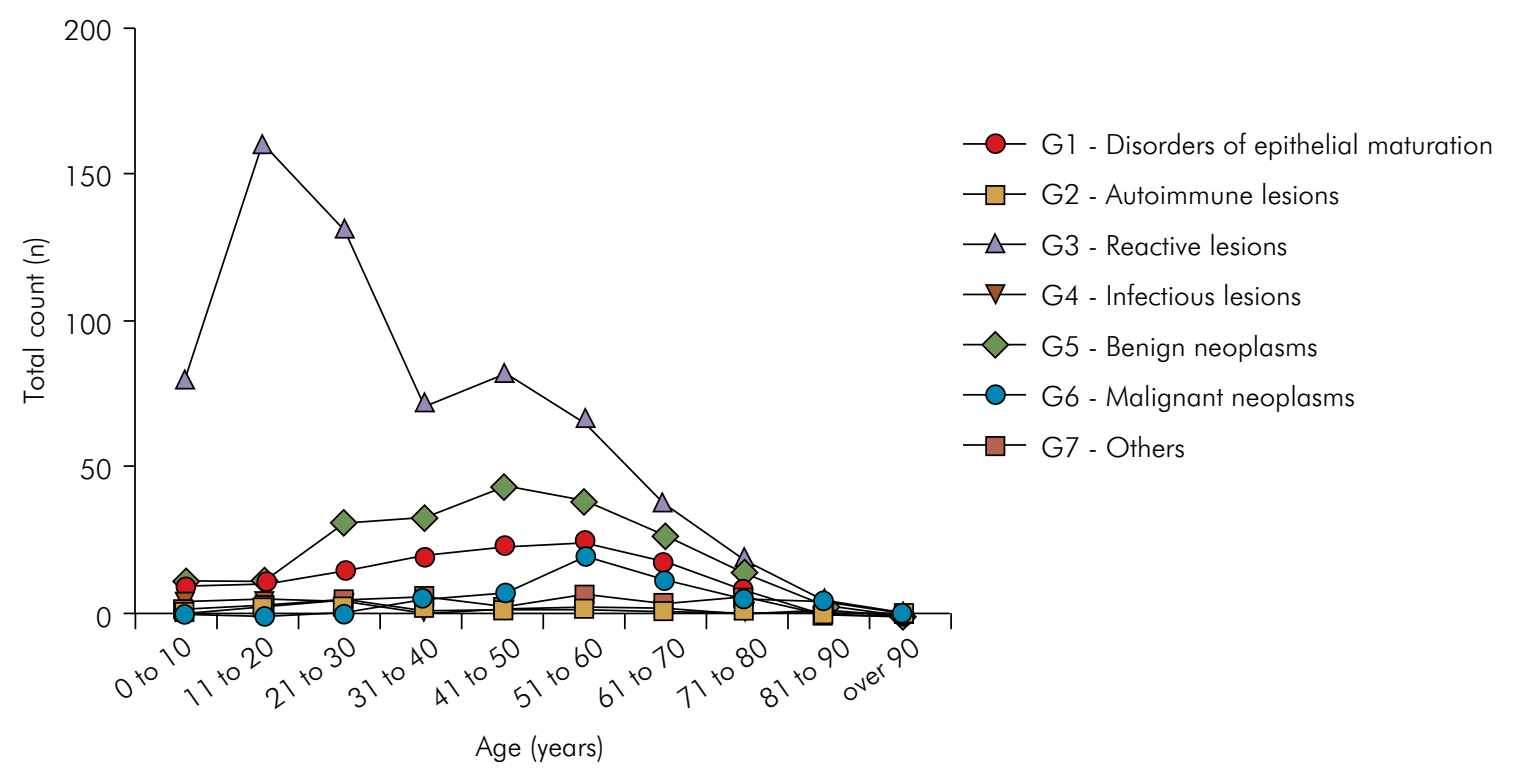

Figure 1. Distribution of all lip lesions ( $n=1195$ ) according to type and age.

\section{Accuracy of clinical examination for diagnosis of PMD and malignant lip lesions}

In the analysis of whether initial clinical screening was accurate for PMD and malignant lesions, we excluded cases with descriptive histopathological diagnoses and those with missing clinical diagnoses. The sensitivity $(88.3 \%)$, specificity $(98.2 \%)$, and accuracy $(97.4 \%)$ of clinical diagnoses of PMD and malignant lesions combined, obtained by comparing provisional clinical diagnoses with final histopathological diagnoses, were excellent (Table 5).

\section{Discussion}

This study is the first to assess the accuracy of clinical diagnoses of PMD and malignant lip lesions. It is also the largest epidemiological study to date of clinical and histopathological data from benign and malignant lip lesions. Our sample was composed of a wide range of lesions with different etiologies; lesions were predominantly reactive and inflammatory. Clinical diagnosis of autoimmune and reactive lesions showed a high degree of sensitivity. More importantly, clinical examination showed a high degree of accuracy and high predictive value 
for the diagnosis of PMD and malignant lip lesions. These findings strengthen the evidence supporting immediate biopsy and histopathological examination in cases of suspected malignancy. Conversely, they suggest that follow up is sufficient for cases with no

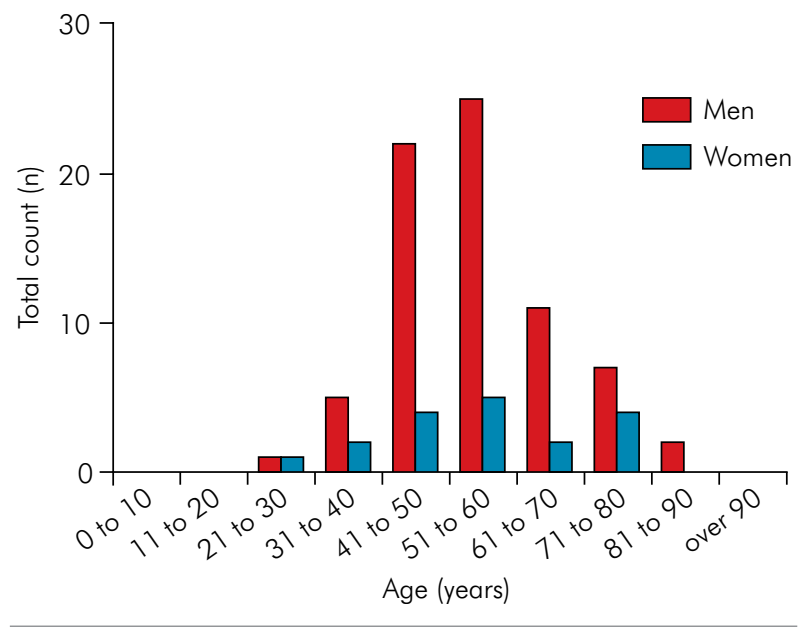

Figure 2. Distribution of potentially malignant and malignant lesions $(n=103)$ according to age and sex.

Table 2. Sensitivity test values for clinical examination and diagnosis of lip lesions according to groups of histopathological diagnoses.

\begin{tabular}{lc}
\hline Groups & Sensitivity \\
\hline G1 - Epithelial disorders & 0.42 \\
G2 - Autoimmune lesions & 0.77 \\
G3 - Reactive lesions & 0.72 \\
G4 - Infectious lesions & 0.40 \\
G5 - Benign neoplasms & 0.55 \\
G6 - Malignant lesions & 0.57 \\
G7 - Others & 0.34 \\
Total & 0.62 \\
\hline
\end{tabular}

suspected malignancy. Although these results are promising, they should be interpreted with caution, given the biases inherent to this cross-sectional retrospective study (e.g., population selection, high degree of interexaminer variability).

Regardless of anatomic region, clinical examination is usually not sufficient for accurate diagnosis; histopathological examination is essential for appropriate clinical decision making. ${ }^{22,23}$ Several studies ${ }^{15,17,18}$ of oral lesions have been based only on clinical data, with no report of histopathological characteristics. Microscopic evaluation is understood to be required to establish the final diagnosis and, thus, the appropriate treatment in all cases of PMD and malignant lesions. ${ }^{19,20}$ In many clinical cases, the lines dividing diagnoses of benign, PMD, and malignant lesions are very thin; clinicians face the challenges of formulating diagnostic hypotheses and predicting which PMD lesions will progress to malignancy. ${ }^{33}$ A recent systematic review assessed the diagnostic accuracy of adjunctive tests combined with oral examination for oral cancer; due to the overall poor quality of studies included, the authors failed to identify a replacement for biopsy and histological assessment for final diagnosis. ${ }^{34}$ However, the accuracy of initial clinical assessment of lip lesions observed in this study suggests that this type of examination alone can be reliable. The study results further suggest that periodic follow up is appropriate in cases with no suspicion of malignancy. These findings are very valuable, given that initial examination is performed at the primary care level in various scenarios. ${ }^{35,36}$ These findings, however, should be interpreted with caution, as many factors, such as training and

Table 3. Distribution of all cases $(n=1195)$ between clinical and histopathological diagnosis according to malignancy.

\begin{tabular}{|c|c|c|c|c|c|}
\hline \multirow{2}{*}{ Clinical diagnosis } & \multicolumn{4}{|c|}{ Histopathological diagnosis } & \multirow{2}{*}{ Total } \\
\hline & Malignant lesion & Potentially malignant disorder & Non-malignant lesion & Descriptive & \\
\hline Malignant lesion & $30(53.6 \%)$ & $2(5.3 \%)$ & $11(1.1 \%)$ & $4(3.8 \%)$ & 47 (3.9\%) \\
\hline Potentially malignant disorder & $4(7.1 \%)$ & $22(57.9 \%)$ & $4(0.4 \%)$ & 37 (35.2\%) & $67(5.6 \%)$ \\
\hline Non-malignant lesion & $5(8.9 \%)$ & $4(10.5 \%)$ & $834(83.7 \%)$ & 35 (33.4\%) & $878(73.5 \%)$ \\
\hline Differential diagnosis* & 7 (12.5\%) & $3(7.9 \%)$ & $6(0.6 \%)$ & $2(1.9 \%)$ & $18(1.5 \%)$ \\
\hline No clinical diagnosis & 10 (17.9\%) & 7 (18.4\%) & $141(14.2 \%)$ & 27 (25.7\%) & $185(15.5 \%)$ \\
\hline Total & $56(100 \%)$ & 38 (100\%) & $996(100 \%)$ & 105 (100\%) & $1195(100 \%)$ \\
\hline
\end{tabular}

*18 cases of differential diagnosis between a malignant or potentially malignant lesion and a non-malignant lesion. 
experience, can affect clinicians' decision making in individual settings. ${ }^{37}$ These factors were not considered in this study.

Cancerous lip lesions are often preceded by noticeable changes in the oral or lip mucosa, also known as PMD; this process allows clinicians to detect and effectively treat lesions in the early stages of oral carcinogenesis. ${ }^{38}$ The high degree of accuracy and high positive and negative predictive values (81.9\% and $98.9 \%$, respectively) for clinical diagnosis of PMD and malignant lip lesions in this study reflect clinicians' ability to discern the nature of these cases correctly. The overall accuracy and sensitivity of clinical diagnosis found in this study are greater than reported in previous studies, ${ }^{20,26}$ but this difference must be interpreted with caution, given that our sample included only lip lesions. On the other hand, the sensitivity of clinical diagnosis of malignant lesions and disorders of epithelial maturation separately was lower (57\% and 52\%, respectively). Final histopathological diagnoses were classified as missing in more than 100 cases due to missing information about lesion location and characteristics or failure to follow standard recommendations for biopsy. This has been reported previously, ${ }^{21}$ and, we stress the importance of a good standard biopsy procedure for histological assessment to avoid incomplete diagnosis and/or misdiagnosis.

This study adds to the body of evidence regarding the distribution of lip pathologies in all age groups. Two previous studies assessed the frequency of lip lesions using histopathological data. ${ }^{14,39}$ A study conducted in Brazil ${ }^{14}$ involved the retrospective analysis of clinical and histopathological data from 1034 lip lesions diagnosed over a 5-year period in five pathology centers. The authors reported no sex predilection and an age range encompassing the first through the ninth decades of life. Most (59.5\%) lesions were reactive or inflammatory, followed by malignant $(21.7 \%)$ and benign (19.1\%) tumors. The most common lip lesion was mucocele (28.4\%), and the lower lip was the most commonly affected region. ${ }^{14}$ Our results corroborate these findings with respect to the absence of sex predilection, the wide age range, and the predominance of mucocele and lower lip location. Although we also found that reactive lesions were most common, they were followed in occurrence frequency by benign tumors and disorders of epithelial

Table 4. Distribution of cases after grouping PMD and malignant lesions in one category for assessment of accuracy, sensitivity and specificity.

\begin{tabular}{|c|c|c|c|}
\hline \multirow{2}{*}{ Clinical diagnosis } & \multicolumn{2}{|c|}{ Histopathological diagnosis } & \multirow{2}{*}{ Total } \\
\hline & Malignant or potentially malignant lesion & Non-malignant lesion & \\
\hline Malignant or potentially malignant lesion & 68 & 15 & 83 \\
\hline Non-malignant lesion & 9 & 840 & 849 \\
\hline Total & 77 & 855 & 932 \\
\hline
\end{tabular}

Fisher's exact test, $\mathrm{p}<.001$

Table 5. Accuracy, predictive value, sensitivity and specificity of clinical examination for PMD and malignant lesions in the lips.

\begin{tabular}{lccc}
\hline Variable & Estimate & \multicolumn{2}{c}{ 95\% Confidence interval } \\
\cline { 3 - 3 } & & Lower limit & Upper limit \\
\hline Disease occurrence & $8.3 \%$ & $6.6 \%$ & $10.2 \%$ \\
Sensitivity & $88.3 \%$ & $79.1 \%$ & $94.5 \%$ \\
Specificity & $98.2 \%$ & $97.1 \%$ & $99.1 \%$ \\
Positive likelihood ratio & 50.3 & 30.28 & 83.67 \\
Negative likelihood ratio & 0.12 & 0.06 & 0.22 \\
Positive predictive value & $81.9 \%$ & $71.9 \%$ & $89.5 \%$ \\
Negative predictive value & $98.9 \%$ & $98.0 \%$ & $99.5 \%$ \\
Accuracy & $97.4 \%$ & - & - \\
\hline
\end{tabular}


maturation. Other authors have described similar clinical findings, ${ }^{15,39,40}$ but the studies are marked by important methodological variations (e.g., sample size, inclusion of only benign lesions).

The present findings are derived from the analysis of records collected over a 65-year period in an oral pathology diagnostic service, which receives specimens from the public health system and private practitioners, as well as from students supervised by oral pathologists and oral surgeons. We could not assess exposure to risk factors, such as tobacco use, alcohol consumption, and UV radiation, as patient records contained no such information in most older cases. Furthermore, we lacked information about biopsy type. Nevertheless, as oral lesions are usually small, excisional biopsy is performed as definitive treatment in most cases. ${ }^{22}$ In addition, data on the year of sample collection and analysis were not accessible. An important factor that should be taken into account is that much has changed in the diagnostic sciences over the study period, creating a potential source of bias.

In this retrospective analysis of data from a representative population with lip lesions, we calculated the specificity and sensitivity of clinical examination of lip lesions. Considering the cross-sectional and retrospective nature of this study, we emphasize the need for largescale prospective studies with consecutive subject recruitment to further examine the accuracy of the clinical diagnosis of oral lesions.

\section{Conclusion}

Clinical examination of the lips showed a high degree of accuracy for the detection of PMD and malignant lesions, indicating good reliability.

\section{References}

1. Siegel RL, Miller KD, Jemal A. Cancer statistics, 2016. CA Cancer J Clin 2016;66(1):7-30. doi:10.3322/caac.21332

2. Ferlay J, Soerjomataram I, Dikshit R, Eser S, Mathers

$\mathrm{C}$, Rebelo $\mathrm{M}$ et al. Cancer incidence and mortality worldwide: sources, methods and major patterns in GLOBOCAN 2012. Int J Cancer. 2015;136(5):E359-86. doi:10.1002/ijc.29210

3. Boing AF, Peres MA, Antunes JL. Mortality from oral and pharyngeal cancer in Brazil: trends and regional patterns, 1979-2002. Rev Panam Salud Publica. 2006;20(1):1-8. doi:10.1590/S1020-49892006000700001

4. Warnakulasuriya S. Living with oral cancer: epidemiology with particular reference to prevalence and life-style changes that influence survival. Oral Oncol. 2010;46(6):407-10. doi:10.1016/j.oraloncology.2010.02.015

5. Carvalho AL, Nishimoto IN, Califano JA, Kowalski LP. Trends in incidence and prognosis for head and neck cancer in the United States: a site-specific analysis of the SEER database. Int J Cancer. 2005;114(5):806-16. doi:10.1002/ijc.20740

6. Howlader NNA, Krapcho M, Garshell J, Miller D, Altekruse SF, Kosary CL et al., editors. SEER cancer statistics review, 1975-2013. Bethesda, MD: National Cancer Institute; 2015. p. 1975-2012.

7. Visscher JG, Waal I. Etiology of cancer of the lip: a review. Int J Oral Maxillofac Surg. 1998;27(3):199-203. doi:10.1016/S0901-5027(98)80010-6

8. Håkansson N, Floderus B, Gustavsson P,

Feychting M, Hallin N. Occupational sunlight exposure and cancer incidence among Swedish construction workers. Epidemiology. 2001;12(5):552-7. doi:10.1097/00001648-200109000-00015

9. Spitzer WO, Hill GB, Chambers LW, Helliwell BE, Murphy HB. The occupation of fishing as a risk factor in cancer of the lip. N Engl J Med. 1975;293(9):419-24. doi:10.1056/NEJM197508282930903

10. Cancer Research UK. Oral cancer incidence statistics. London: Cancer Research UK; 2015 [cited 2015 Sep]. Available from: http://www.cancerresearchuk.org/ health-professional/cancer-statistics/ statistics-by-cancer-type/oral-cancer/incidence

11. Sargeran K, Murtomaa H, Safavi SM, Vehkalahti MM, Teronen O. Survival after lip cancer diagnosis. J Craniofac Surg. 2009;20(1):248-52. doi:10.1097/SCS.0b013e31818431bd

12. Moore S, Johnson N, Pierce A, Wilson D. The epidemiology of lip cancer: a review of global incidence and aetiology. Oral Dis 1999;5(3):185-95. doi:10.1111/j.1601-0825.1999.tb00300.x

13. Neville BW, Day TA. Oral cancer and precancerous lesions. CA Cancer J Clin. 2002;52(4):195-215. doi:10.3322/canjclin.52.4.195

14. Osterne RL, Costa FW, Mota MR, Vidal Patrocínio RM, Alves AP, Soares EC et al. Lip lesions in a Brazilian population. J Craniofac Surg. 2011;22(6):2421-5. doi:10.1097/SCS.0b013e318232a7dc 
15. Patil S, Maheshwari S. Prevalence of lip lesions in an Indian population. J Clin Exp Dent. 2014;6(4):e374-8. doi:10.4317/jced.51597

16. Rathod S, Livergant J, Klein J, Witterick I, Ringash J. A systematic review of quality of life in head and neck cancer treated with surgery with or without adjuvant treatment. Oral Oncol. 2015;51(10):888-900. doi:10.1016/j.oraloncology.2015.07.002

17. Lingen MW, Kalmar JR, Karrison T, Speight PM. Critical evaluation of diagnostic aids for the detection of oral cancer. Oral Oncol. 2008;44(1):10-22. doi:10.1016/j.oraloncology.2007.06.011

18. Bouquot JE. Common oral lesions found during a mass screening examination. J Am Dent Assoc. 1986;112(1):50-7. doi:10.14219/jada.archive.1986.0007

19. Güneri P, Epstein JB. Late stage diagnosis of oral cancer: components and possible solutions. Oral Oncol. 2014;50(12):1131-6. doi:10.1016/j.oraloncology.2014.09.005

20. Onofre MA, Sposto MR, Navarro CM, Motta ME, Turatti E, Almeida RT et al. Potentially malignant epithelial oral lesions: discrepancies between clinical and histological diagnosis. Oral Dis. 1997;3(3):148-52. doi:10.1111/j.1601-0825.1997.tb00026.x

21. Pentenero M, Carrozzo M, Pagano M, Galliano D, Broccoletti R, Scully C et al. Oral mucosal dysplastic lesions and early squamous cell carcinomas: underdiagnosis from incisional biopsy. Oral Dis. 2003;9(2):68-72. doi:10.1034/j.1601-0825.2003.02875.x

22. Oliver RJ, Sloan P, Pemberton MN. Oral biopsies: methods and applications. Br Dent J. 2004;196(6):329-33. doi:10.1038/sj.bdj.4811075

23. Mota-Ramírez A, Silvestre FJ, Simó JM. Oral biopsy in dental practice. Med Oral Patol Oral Cir Bucal. 2007;12(7):E504-10.

24. Patel KJ, De Silva HL, Tong DC, Love RM. Concordance between clinical and histopathologic diagnoses of oral mucosal lesions. J Oral Maxillofac Surg. 2011;69(1):125-33. doi:10.1016/j.joms.2010.07.075

25. Sardella A, Demarosi F, Lodi G, Canegallo L, Rimondini L, Carrassi A. Accuracy of referrals to a specialist oral medicine unit by general medical and dental practitioners and the educational implications. J Dent Educ. 2007;71(4):487-91.

26. Seoane J, Warnakulasuriya S, Varela-Centelles P, Esparza G, Dios PD. Oral cancer: experiences and diagnostic abilities elicited by dentists in North-western Spain. Oral Dis. 2006;12(5):487-92. doi:10.1111/j.1601-0825.2005.01225.x

27. Williams HK, Hey AA, Browne RM. The use by general dental practitioners of an oral pathology diagnostic service over a 20-year period: the Birmingham Dental Hospital experience. Br Dent J 1997;182(11):424-9. doi:10.1038/sj.bdj.4809403

28. Downer MC, Moles DR, Palmer S, Speight PM. A systematic review of test performance in screening for oral cancer and precancer. Oral Oncol 2004;40(3):264-73. doi:10.1016/j.oraloncology.2003.08.013
29. Mathew B, Sankaranarayanan R, Sunilkumar KB, Kuruvila B, Pisani P, Nair MK. Reproducibility and validity of oral visual inspection by trained health workers in the detection of oral precancer and cancer. Br J Cancer 1997;76(3):390-4. doi:10.1038/bjc.1997.396

30. Warnakulasuriya S, Pindborg JJ. Reliability of oral precancer screening by primary health care workers in Sri Lanka. Community Dent Health 1990;7(1):73-9.

31. Warnakulasuriya S, Johnson NW, van der Waal I. Nomenclature and classification of potentially malignant disorders of the oral mucosa. J Oral Pathol Med. 2007;36(10):575-80. doi:10.1111/j.1600-0714.2007.00582.x

32. De Luca Canto G, Pachêco-Pereira C, Aydinoz S, Major PW, Flores-Mir C, Gozal D. Diagnostic capability of biological markers in assessment of obstructive sleep apnea: a systematic review and meta-analysis. J Clin Sleep Med. 2015;11(1):27-36. doi:10.5664/jcsm.4358

33. Scully C. Challenges in predicting which oral mucosal potentially malignant disease will progress to neoplasia. Oral Dis. 2014;20(1):1-5. doi:10.1111/odi.12208

34. Macey R, Walsh T, Brocklehurst P, Kerr AR, Liu JL, Lingen MW et al. Diagnostic tests for oral cancer and potentially malignant disorders in patients presenting with clinically evident lesions. Cochrane Database Syst Rev. 2015;5:CD010276. doi:10.1002/14651858.CD010276.pub2.

35. Brocklehurst PR, Baker SR, Speight PM. A qualitative study examining the experience of primary care dentists in the detection and management of potentially malignant lesions. 2. Mechanics of the referral and patient communication. Br Dent J. 2010;208(2):E4. doi:10.1038/sj.bdj.2010.55

36. Waal I, Bree R, Brakenhoff R, Coebergh JW. Early diagnosis in primary oral cancer: is it possible? Med Oral Patol Oral Cir Bucal. 2011;16(3):e300-5. doi:10.4317/medoral.16.e300

37. Hassona Y, Scully C, Shahin A, Maayta W, Sawair F. Factors influencing early detection of oral cancer by primary health-care professionals. J Cancer Educ. 2016;31(2):285-91. doi:10.1007/s13187-015-0823-2

38. Mignogna MD, Fedele S, Lo Russo L, Ruoppo E, Lo Muzio L. Costs and effectiveness in the care of patients with oral and pharyngeal cancer: analysis of a paradox. Eur J Cancer Prev. 2002;11(3):205-8. doi:10.1097/00008469-200206000-00002

39. Ntomouchtsis A, Karakinaris G, Poulolpoulos A, Kechagias N, Kittikidou K, Tsompanidou C et al. Benign lip lesions. A 10-year retrospective study. Oral Maxillofac Surg. 2010;14(2):115-8. doi:10.1007/s10006-009-0196-y

40. Bouquot JE, Gundlach KK. Odd lips: the prevalence of common lip lesions in 23,616 white Americans over 35 years of age. Quintessence Int. 1987;18(4):277-84. 